\title{
Education Programmes in Nursing: A Mini Review from Evidences
}

\author{
Aziz Shahraki Vahed ${ }^{1}$, Enayatollah Safarzaei ${ }^{2}$ \\ ${ }^{1}$ Faculty of Nursing and Midwifery, Zabol University of Medical Sciences, Zabol, Iran \\ ${ }^{2}$ Master Student of Medical- Surgical Nursing, Zahedan University of Medical Science, zahedan, Iran
}

\begin{abstract}
Aim: The aim of this paper is to review the literature on what facilitates or inhibits continuing education in nursing and to identify ways to make continuing education more effective. Background. Healthcare professionals have always been encouraged to update their knowledge and maintain clinical competence. The rapid changes currently taking place within healthcare systems have increased the pressure from direct care providers, professional bodies and the general public for nurses to engage in continuing education programmes. Despite a growing body of empirical research on this topic, the effectiveness and impact of continuing education remains underexplored. Method. A literature search was conducted in January 2005 using CINAHL, Medline, the Cochrane databases and the Internet. Keywords used were: 'continuing education', 'professional development', 'viability of continuing education/professional development programmes', 'evaluation of continuing education/professional development programmes' and 'effectiveness of continuing education/professional development programmes'. No date restrictions were imposed. Results. Factors that facilitate the implementation of continuing education in nursing arise from individual, professional and organizational perspectives. While the philosophy behind continuing education is to encourage nurses to become lifelong learners, the learning method chosen for such programmes is often didactic in nature, as opposed to encouraging nurses to take initiative and direct their own learning. Continuing education is intended to ensure healtheare practitioners' knowledge is current, but it is difficult to determine if those who attend these courses are implementing what they have learnt. Conclusion. To make continuing education programmes more effective, nurses need to have a more participatory role in their learning. A concerted effort should be made to make continuing education attainable and realistic.
\end{abstract}

Keywords: Education; Programmes; Nursing; Mini Review; Evidences

\section{Introduction}

The importance of continuing education has been increasingly debated in nursing literature over the past few years. It is of international concern to policymakers and stakeholders in the healthcare sector and is reflected in various statutes, such as the Nurse, Midwives and Health Visitors Act (1979) and recommendations of the National Staff Committee for Nurses and Midwives (1981) in the United Kingdom (UK), the Pew Health Profession Commission Reports (1995, 1998 in the United States (US), and the National Nursing Competency Project (1997) and Canadian Nurses Association Policy Statement (1998) in Canada. Yet, despite the obvious importance of continuing education to the nursing profession, and the extensive involvement of various stakeholders, little is known about whether continuing education works in practice. A literature review was therefore undertaken to examine discussion papers and studies on continuing education and the factors that affect its value in nursing.

\section{Methods and Materials}

Search methods: A computerized search up to January 2005 was conducted using CINAHL, Medline, the Cochrane databases and the Internet. This was followed by a literature search of relevant references in the studies included. The keywords used in the search included 'continuing education', 'professional development', 'viability of continuing education/professional development programmes', 'evaluation of continuing education/ professional development programmes' and 'effectiveness of continuing education/professional development programmes'. Articles meeting the following criteria were retained for further analysis: (a) articles/studies whose main content was specific to continuing education as opposed to formal education; (b) articles/studies whose content was specific to viability/effectiveness/evaluation of continuing education in healthcare disciplines; (c) articles/studies which were peer reviewed, as opposed to anecdotal literature; and (d) articles/ studies which were published in an English language journal. This literature review will focus on the potential impact of continuing education on nursing competence and on lifelong learning. It will not include literature on philosophy in nurse education, adult learning principles or specific curricular approaches to adult learning. Results A total of 40 articles met the selection criteria and were used in the review. Most of the articles/studies were conducted by researchers in nursing and ancillary healthcare disciplines in the UK, US and Canada. The geographical and disciplinary distribution of these studies suggests that continuing education is a matter of widespread concern. The scope of these studies conveniently enables comparison of similarities and differences between professions and countries. However, the research has tended to be somewhat fragmented and fails to provide a unified picture in terms of the effectiveness of continuing education from a practical point of view. Most of the studies reviewed, tended to be restricted to evaluation of isolated continuing education programmes. The literature also revealed a lack of needs analyses underpinning continuing education programmes and a failure to evaluate outcomes of programmes taking into account clients' views and experience or health professionals' performance. 


\section{International Journal of Science and Research (IJSR) \\ ISSN (Online): 2319-7064}

Index Copernicus Value (2013): 6.14 | Impact Factor (2015): 6.391

Moreover, none of the studies reviewed were followed up or validated through replication. Hence, it may be argued that while most of the research on continuing education is appropriate for individual programmes, on a universal level it is rather patchy and has limited generalizability. This review attempts to discuss whether the broad aims of continuing education are being met, as well as to identify the gaps in research that need to be addressed to make continuing education more effective by ensuring that nurses are safe and competent to practice.

Continuing education methods Both the English National Board (ENB) for Nursing, Midwifery and Health Visiting (1990) and American Nurses Association (ANA) (1994) define continuing education as any postbasic nursing education aimed at actively engaging nurses in a lifelong process of learning, with the ultimate goal of improving delivery of health care. They assert that the intent behind continuing education is to help nurses take the initiative and cultivate an aptitude for lifelong learning. Continuing education in nursing is necessary because of an unprecedented growth in professional knowledge, rapid changes in the healthcare system and the consequent changes in nurses' roles (Glazer 1999, Lundgren \& Houseman 2002, Brunt 2003). Health practitioners need to adapt as professional requirements change to maintain competence and to safeguard the public. However, while there is some agreement about the aim of continuing education, there appears to be no consensus in the literature reviewed on what constitutes continuing education (Barriball et al. 1992, Lawton \& Wimpenny 2003). Some authors focus only on structured and planned activity and prefer to treat any selfdirected learning as a separate entity (Lawton \& Wimpenny 2003). In contrast, other authors adopt a more inclusive approach to continuing education. They claim that it is more than structured study days and O. Griscti and J. Jacono 450

2006 The Authors. Journal compilation 2006 Blackwell Publishing Ltd courses and should be an all-encompassing term that covers any self-directed initiative that nurses might take (Furze \& Pearcey 1999, Brunt 2003).

\section{Identifying Needs}

While continuing education needs to become more student centred, it is equally important to identify other stakeholders and their needs (Lawton \& Wimpenny 2003). As well as individual practitioners, these include employers and professional bodies. With regard to individual practitioners, some nurses may only participate in continuing education programmes to meet the requirements of the statutory bodies which periodically revalidate nurses' right to practice (Grossman 1998, Lawton \& Wimpenny 2003). However, a number of studies indicate that nurses also participate in continuing education out of a desire to further their knowledge. This finding appears common across countries, being reported in studies conducted in both the UK (Lindsay 1990, Larcombe \& Maggs 1991, Turner 1991, Thurston 1992) and US (O’Connor 1992, Waddell 1993). O’Connor (1992) asked nurses to indicate their reasons for participating in continuing education. Respondents identified seven motivational factors, with improving professional knowledge and skills rated the highest. Turner (1991) reported that nurses cited personal satisfaction, joy of learning, increased knowledge of new techniques and self-assurance as benefits gained from continuing education. In a meta-analysis of 22 studies on why nurses participate in continuing education, Waddell (1993) indicated that motivational orientation was the major reason nurses participated in continuing education programmes. Although external pressures such as recertification, relicensure and employer expectations featured highly in this study, they were marginally surpassed by cognitive interest, i.e. learning for its own sake. All these studies suggest that nurses have a strong interest in continuing education. However, as Waddell (1993) remarks most studies were limited to nurses who had participated in continuing education programmes. Studies including nurses with no known history of participation in continuing education programmes might yield different findings, thus providing a more complex picture. It argued that the driving force behind continuing education goes beyond satisfying individual needs (Grossman 1998). There is increasing pressure from the public, who Integrative literature reviews and meta-analyses Effectiveness of continuing education programmes in nursing 2006 The Authors. Journal compilation 2006 Blackwell Publishing Ltd 451 are pushing health authorities to ensure that health professionals are safe practitioners. In turn, the concerns of employers and professional bodies have provided an impetus to use regulatory action as a means to ensure currency of knowledge and competence in practice (Grossman 1998, Eustace 2001, Glazer 1999). However, employers and professional bodies have different reasons for requiring healthcare professionals to remain competent. Healthcare authorities are mainly concerned with the costs of providing high quality care and protecting themselves against potential litigation (Brunt 2003). Professional bodies' interests are to advance professional development, to ensure autonomy and to preserve self-regulation (Grossman 1998). In addition, it appears that while professional bodies may be more interested in advancing the profession's body of knowledge through their members' lifelong learning and research, healthcare authorities may be more focused on addressing immediate and short-term needs such as orientation programmes, in-service training and acquisition of new skills, rather than lifelong learning (Lawton \& Wimpenny 2003). These differing mandates may lead to tensions when it comes to planning for continuing education programmes, even though the goals of both are ultimately similar: to protect the public from malpractice by ensuring safe, competent client care (Grossman 1998, Lawton \& Wimpenny 2003). The differing mandates of healthcare authorities and professional bodies may also explain why, in many countries, continuing education programmes tend to be provided by two separate entities: the hospital/organization that employs the nurse and the national/provincial nursing statutory body that regulates professional practice. In the meantime, nurses are caught in the middle, undertaking (and often financing) continuing education courses, but not involved in their evolution (Nolan et al. 1995). Marginalization of nurses may further occur when, as Glazer (1999) argues, politics influence the direction which continuing education needs to take. There are times, Glazer (1999) argues, when what is ideal has to be sacrificed to political and practical realities. Thus, if the 


\section{International Journal of Science and Research (IJSR) \\ ISSN (Online): 2319-7064}

Index Copernicus Value (2013): 6.14 | Impact Factor (2015): 6.391

public is pushing organizations or professionals to address certain issues, nurses may feel obliged to comply with organizational or professional demands rather than pursue their own needs. Ultimately, the success of continuing education policies and programmes can be greatly enhanced by including all stakeholders in discussions prior to implementation (Grossman 1998). However, the literature critiqued in this review suggests that, in fact, most continuing education programmes are based on the needs of single stakeholder groups, and rarely on a consensus of all interested groups. A needs assessment of all parties involved becomes particularly crucial if continuing education is to be imposed as a mandatory requirement.

\section{Mandatory vs. voluntary participation}

The issue of mandatory continuing education in nursing is a contentious one. An increasing number of policy directives advocate mandatory participation in continuing education programmes (Eustace 2001, Brunt 2003). This policy suggestion arises, in part, out of concern that voluntary participation in continuing education might result in a lack of commitment by some nurses (Lundgren \& Houseman 2002). Carpenito (1991) suggests that while the majority of people in a professional group are interested in advancing their education, as in any other profession, there are a number of 'laggards' who do not show any interest at all. It is this group of laggards that Carpenito (1991) suggests should be the focus of continuing education policies. Such policies should encourage this group to give up their isolation and move toward lifelong learning.

\section{Evaluating outcomes and impact}

One way to determine how much time practitioners should spend on continuing education programmes is to obtain some form of measure that indicates when the goal of continuing education has been achieved. Continuing education is intended to enable nurses to pursue their professional development and to fulfil the demands of their role safely and competently. However, few empirical studies show how continuing education actually affects practice in the UK (Barriball et al. 1992, Furze \& Pearcey 1999, Jordan 2000) or in the US (Eustace 2001). Most of these studies rely solely on the health professionals' perceptions of change, which does not necessarily equate to improvement in patient care. Theoretically, an appropriate way to evaluate any change in behavioural patterns is through observational studies. Jordan (2000) identified five observational studies that were being undertaken in nursing. However, as Jordan points out, the practical, ethical and budgetary difficulties in carrying out such studies, as well as an increased risk of the Hawthorne effect, are potential pitfalls of this method of enquiry. Another possible approach to evaluating patient outcomes is through patient surveys. Once more, there appears to be a dearth of research using this method. In their literature review, Furze and Pearcey (1999) commented that there were no UK and only two US studies that used this method.

\section{Conclusion}

From the literature reviewed it appears that continuing education has attracted considerable attention in the nursing profession. However, it is also evident that research into the topic has been restricted to evaluation of isolated structured continuing education programmes that were not validated through replication. Whilst this may seem to present a fragmented picture of whether or not continuing education programmes work in practice, nevertheless it does demonstrate an increasing awareness, as well as initiatives, to keep nurses' knowledge and skills up to date. Direct-care personnel shortages and pervasive underfunding have conspired to make life-long learning a difficult undertaking in nursing and related disciplines. In spite of this, the growing numbers of diploma-trained nurses who go on to obtain a degree, and the increasing number of new, university-trained nurses, suggest that a thirst for knowledge, and thus quality healthcare delivery, continue to exist in the nursing profession. The goal now should be to keep that motivation alive. In this sense, educators have a pivotal role to play. Educators can help to sustain this enthusiasm in nurses who want to learn, and also stimulate similar eagerness in lessmotivated nurses, simply by involving learners more. It was noted in the literature reviewed that participatory workshops seem to enthuse nurses more than didactic lectures; this suggests the need for more student-centred approaches when planning continuing education programmes. Likewise, continuing education can be exciting if educators make learning experiences diverse and appealing. Educators should take time to assess learning styles and adopt different learning strategies, when planning or executing continuing education programmes in order to take account of different learning needs. Similarly, organizations should adopt a more participatory approach to address continuing education in nursing. From this literature review, there appears to be a rift between the needs and desires of various stakeholders in health care and nurses. Organizations and professional bodies need to be more aware of what nurses want to learn, as well as to understand factors such as poor working conditions, understaffing and family commitments which may hinder some nurses from pursuing further education. It is encouraging that all sides in the healthcare system recognize the value of continuing education for nurses; however, more needs to be done to bring all sides together to identify the learning needs of all parties and overcome differences. Hence, health authorities and professional bodies should demonstrate a commitment to involving nurses in the organization process from the initial stages of planning continuing education programmes, to the evaluation of organized learning experiences.

\section{References}

[1] American Nurses Association (1994) Standards for Professional Development. American Nurses Association, Kansas City, MO.

[2] Barriball L.K., While A.E. \& Norman I.J. (1992) Continuing professional education for nurses: a review of the literature. Journal of Advanced Nursing 17, 1129-1140.

[3] Brunt B.A. (2003) The Importance of Life Long Learning in Managing Risks. The Nursing Management Risk Series. 


\section{International Journal of Science and Research (IJSR) \\ ISSN (Online): 2319-7064}

Index Copernicus Value (2013): 6.14 | Impact Factor (2015): 6.391

Retrieved

from

http://www.nursingworld.org/mods/archive/mod311/cerm2 ful.htm on 29 July 2003.

[4] Bullock L.F., Libbus M.K., Lewis S. \& Gayer D. (2002) Continuing education: improving perceived competence in school nurses. Journal of School Nursing 18(6), 360-363.

[5] Canadian Nurses Association (1997) National Nursing Competency Project Final Report. CNA, Ottawa.

[6] Canadian Nurses Association Policy Statement (1998) Educational Support for Competent Nursing Practice. CNA, Ottawa.

[7] Carpenito J. (1991) A lifetime of commitment. Nursing Times 87(48), 53-55.

[8] Diers D. (1985) Policy and politics. In Political Action Handbook for Nurses (Mason D. \& Talbot S., eds), Addison-Wesley, Menlo Park, CA, p. 54.

[9] English National Board for Nursing, Midwifery and Health Visiting (1990) Framework for Continuing Professional Education for Nurses, Midwives and Health Visitors, Guide to Implementation. ENB, London.

[10] Eustace L.W. (2001) Mandatory continuing education; past, present, and future trends and issues. Journal of Continuing Education in Nursing 32(3), 133-137.

[11] Furze G. \& Pearcey P. (1999) Continuing education in nursing: a review of the literature. Journal of Advanced Nursing 29(2), 355-363.

[12] Gill K.P. \& Ursic P. (1994) The impact of continuing education on patient outcomes in the elderly hip fracture population. Journal of Continuing Nursing Education 25(4), 181-185.

[13] Glazer G. (1999) The policy and politics of continued competence. Online Journal of Issues in Nursing. Retrieved from http:// www.nursingworld.org/ojin/tpclg/leg_8.htm on 6 August 2003.

[14] Grossman J. (1998) Continuing competence in the health professions. The American Journal of Occupational Therapy 52(9), 709-715.

[15] Jordan S. (1998) From classroom theory to clinical practice: evaluating the impact of a post registration course. Nurse Education Today May(18), 293-302.

[16] Jordan S. (2000) Educational Input and patient outcomes: exploring the gap. Journal of Advanced Nursing 31(2), 461-471.

[17] Jordan S., Coleman M., Hardy B. \& Hughes D. (1999) Assessing educational effectiveness: the impact of a specialist course on the delivery of care. Journal of Advanced Nursing 30(4), 789-807.

[18] Larcombe K. \& Maggs C. (1991) Processes for Identifying the Continuing Professional Education Needs of Nurses, Midwives and Health Visitors: An Evaluation. English National Board, London.

[19] Lawton S. \& Wimpenny P. (2003) Continuing professional development: a review. Nursing Standard 26(17), 24, 4144. Lindsay B. (1990) Assessing the demand for continuing education. Nursing Times 86(29), 50.

[20] Lundgren B.S. \& Houseman C.A. (2002) Continuing competence in selected health care professions. Journal of Allied Health 31(4), 232-240.

[21] McLeod E., MacTavish M., Morris A. \& Allan J. (1994) The challenges of continuing educational program evaluation . Gerontology Certificate Program. Perspectives 18(4), 2-7. National Staff Committee for Nurses and Midwives (1981) Recommendations on the Organisation and Provision of Continuing In-Service Education and Training.
[22] National Staff Committee for Nurses and Midwives, London. Nielson B.B. \& Miaskowski C.A. (1987) The influence of an Oncology Nursing Continuing Education Program on Nursing Practice. Journal of Continuing Education in Nursing 18(6), 193-199.

[23] Nolan M., Owens R.G. \& Nolan J. (1995) Continuing professional education: identifying the characteristics of an effective system. Journal of Advanced Nursing 21, 551560. Nurse, Midwives and Health Visitors Act (1979) HMSO. London.

[24] Nursing and Midwifery Council (2004) The Prep Handbook. NMC, London. O'Brien T., Freemantle N., Oxman A.D., Wolf F., Davies D.A. \& Herrin J. (2003) Continuing education meetings and workshops: effects on professional practice and health care outcomes. The Cochrane Library, Issue 2, 2003, Oxford. Integrative literature reviews and meta-analyses Effectiveness of continuing education programmes in nursing 2006 The Authors. Journal compilation 2006 Blackwell Publishing Ltd 455

[25] O'Connor A.B. (1992) Reasons nurses participate in continuing education. Nursing Research 28(6), 354-359.

[26] Pew Health Profession Commission Reports (1995) Reforming Health Care Workforce Regulation: Policy Considerations for the 21st Century. Pew Health Professions Commission, San Francisco, CA.

[27] Pew Health Profession Commission Reports (1998) Strengthening Consumer Protection: Priorities for Health Care Workforce Regulation. Pew Health Professions Commission, San Francisco, CA.

[28] Puetz B.E. (1980) Differences between Indiana registered nurse attenders and non attenders in continuing education in nursing activities. Journal of Continuing Education in Nursing 11(2), 19-26.

[29] Registered Nurses Association of Ontario Project (1999) Best Practice Guidelines. Retrieved from http://www.rnao.org/bestpractices/ on 5 May 2005.

[30] Scho" n D. (1983) The Reflective Practitioner. How Professionals Think in Action. Temple Smith, London.

[31] Senge P.M. (1990) The Fifth Discipline. The Heart and Practice of Learning Organization. Doubleday, New York.

[32] Thurston H.I. (1992) Mandatory continuing education: what the research tells us. Journal of Continuing Education in Nursing 23(1), 6-14.

[33] Timms J. \& Ford P. (1995) Registered Nurses perceptions of gerontological continuing education needs in the United Kingdom and in the USA. Journal of Advanced Nursing 22(2), 300-307.

[34] Turner P. (1991) Benefits and costs of continuing education in nursing education: an analytic survey. Journal of Continuing Education in Nursing 22(3), 104-108.

[35] Waddell D.L. (1993) Why do nurses participate in continuing education? a meta-analysis. Journal of Continuing Education in Nursing 24(2), 52-56. 